\title{
Correlation between epidermal growth factor receptor mutations and the expression of estrogen receptor- $\beta$ in advanced non-small cell lung cancer
}

\author{
FANG DENG ${ }^{1,2}$, MING LI $^{1,2}$, WU-LIN SHAN ${ }^{2}$, LI-TING QIAN ${ }^{2}$, SHUI-PING MENG ${ }^{3}$, \\ XIAO-LEI ZHANG ${ }^{2}$ and BAO-LONG WANG ${ }^{1}$
}

${ }^{1}$ Department of Clinical Laboratory, Affiliated Provincial Hospital of Anhui Medical University, Hefei, Anhui 230022; Departments of ${ }^{2}$ Clinical Laboratory and ${ }^{3}$ Respiratory Oncology, Anhui Provincial Cancer Hospital, Hefei, Anhui 230031, P.R. China

Received July 14, 2015; Accepted November 3, 2016

DOI: 10.3892/ol.2017.5711

\begin{abstract}
Epidermal growth factor receptor (EGFR) mutations are more common in non-small cell lung cancer (NSCLC) and in female patients of East Asian origin. Therefore, the present study investigated the presence of EGFR mutations in advanced NSCLC, and assessed its correlation with clinicopathologic factors, including the expression of estrogen receptor- $\beta$ (ER- $\beta$ ) and patient prognosis. The present study performed a retrospective analysis of 83 patients with stage IIIB-IV NSCLC. The expression of ER- $\beta$ and p53 were examined using immunohistochemical methods. EGFR mutations were evaluated using the amplification refractory mutation system. The expression of ER- $\beta$ and p53 were detected in 37 (45.6\%) and 48 (57.8\%) of the patient tumors, respectively. EGFR mutations were identified in $36(45.4 \%)$ cases. EGFR mutations were more frequently observed in ER- $\beta$-negative tumors $(26 / 46 ; 56.5 \%)$, compared with ER- $\beta$-positive tumors $(10 / 37 ; 27 \%)$. The expression of ER- $\beta$ was significantly associated with EGFR mutations with an odds ratio (OR) of $0.241(\mathrm{P}=0.029)$. However, no significant correlation was observed between the expression of p53 and mutations in EGFR ( $\mathrm{OR}=1.792 ; \mathrm{P}=0.340)$. In addition, the expression of ER- $\beta$ and lymph node metastasis were associated with poor prognosis, whereas EGFR mutations were significantly associated with favorable prognosis in terms of progression-free survival rates. However, there was no prognostic significance associated with the expression of p53. In conclusion, the expression of ER- $\beta$ was significantly correlated with the presence of EGFR mutations. The expression of ER- $\beta$ and mutations of EGFR were found to be prognostic factors for survival rates in patients with advanced NSCLC.
\end{abstract}

Correspondence to: Dr Bao-Long Wang, Department of Clinical Laboratory, Affiliated Provincial Hospital of Anhui Medical University, 218 Jixi Road, Shushan, Hefei, Anhui 230022, P.R. China E-mail: baolongwang196@sina.com

Key words: epidermal growth factor receptor, estrogen receptor- $\beta$, non-small cell lung cancer, mutation, p53

\section{Introduction}

Lung cancer is a leading cause of cancer-associated mortality worldwide (1) and is difficult to cure, with a 5-year survival rate of only $1-26 \%$ (2). Although tobacco smoking is the predominant risk factor for lung cancer, $25 \%$ of lung cancer cases are not attributable to tobacco use (3). The increase in lung cancer appears to be a consequence of a marked increase in the prevalence of non-small cell lung cancer (NSCLC). NSCLC is more common in females, is predominantly of the adenocarcinoma cell type, and has less of an association with smoking habits, compared with other histological subtypes of lung cancer (4-6). These clinicopathologic characteristics suggest that gender-dependent factors are involved in the cause and prognosis of NSCLC.

Previous laboratory (2,7-9) and clinical studies (10-13) have reported that estrogen affects the differentiation and maturation of the normal lung, and stimulates lung tumor growth in particular NSCLC tumors $(8,14,15)$. Epidemiological studies have also suggested that exogenous and endogenous estrogen affects the development of lung cancer (16). Several studies have provided evidence to support a biological role for estrogens in lung carcinogenesis by the direct promotion of NSCLC cell proliferation through estrogen receptor (ER)-mediated signaling $(2,17,18)$. ERs, including ER- $\alpha$ and ER- $\beta$, have been shown to be expressed in normal lung tissue and in lung carcinoma, particularly adenocarcinoma $(8,19,20)$. The extent to which ER is expressed in lung tissue remains the subject of controversy, with minimal to almost ubiquitous expression previously reported (21).

In addition to transcriptional activation of estrogen-responsive genes, estrogen has been reported to transactivate growth factor signaling pathways, including the epidermal growth factor receptor (EGFR) pathway. This ER-EGFR signaling axis appears to be reciprocal, with EGFR signaling enhancing the activation of ER, and ER signaling enhancing that of EGFR (22). Following the observation of somatic EGFR mutations in NSCLC, several studies have reported higher mutation frequencies associated with adenocarcinoma, patients of East Asian ethnicity, women and non-smokers $(23,24)$. Given the 
gender bias in the prevalence of EGFR mutations, interactions between the ER and EGFR pathways have been the subject of extensive investigation (12,25-27). However, the majority of studies have focused on stage I-III NSCLC, and few have examined their association with more advanced stages of this disease. In addition, the findings from these studies remain inconsistent.

The aim of the present study was to examine the frequency of EGFR gene mutations in advanced NSCLC, and to assess its correlation with clinicopathologic factors, including the expression of ER- $\beta$ and patient prognosis.

\section{Materials and methods}

Patients. In the present study, a retrospective analysis of a total of 83 patients with advanced NSCLC was performed. The samples analyzed included 17 surgical specimens, 12 lung biopsy specimens, 15 bronchoscopic biopsy specimens, 24 pleural effusion specimens, 13 lymph node biopsy specimens and two bone biopsy specimens. These specimens were fresh frozen or tumors embedded in paraffin blocks. All patients were diagnosed as stage IIIB-IV according to the 1997 revised tumor-node-metastasis classification system of the International Union against Cancer (28). Tumor specimens were collected from the Anhui Provincial Hospital (Hefei, China) between August 2011 and August 2013. Written informed consent was provided by all patients. Approval was obtained from the institutional review board and ethics committee of Anhui Provincial Hospital. The clinical features of the patients are listed in Table I.

EGFR mutation analysis. Mutations in exons 18-21 of the EGFR gene were detected using methods described previously (29). Briefly, genomic DNA was extracted and purified from either fresh-frozen tumors or tumors embedded in paraffin blocks using the QIAamp DNA FFPE Tissue kit (catalog no., 56404; Qiagen GmbH, Hilden, Germany). A 296-base pair GAPDH fragment was amplified as an internal control to ensure DNA integrity and for normalization. Primer pairs used were as follows: exon 18 sense, 5'-CAAATGAGCTGGCAAGTGCCG TGTC-3' and antisense, 5'-GAGTTTCCCAAACACTCAGTG AAAC-3'; exon 19 sense, 5'-GCAATATCAGCCTTAGGT GCGGCTC-3' and antisense, 5'-CATAGAAAGTGAACA TTTAGGATGTG-3'; exon 20 sense, 5'-CCATGAGTACGT ATTTTGAAACTC-3' and antisense, 5'-CATATCCCCATG GCAAACTCTTGC-3'; exon 21 sense, 5'-CTAACGTTCGCC AGCCATAAGTCC-3' and antisense, 5'-GCTGCGAGCTCA CCCAGAATGTCTGG-3'. Genomic DNA was extracted and purified from either fresh-frozen tumors or tumors embedded in paraffin blocks using the QIAamp DNA FFPE Tissue kit (catalog no., 56404; Qiagen $\mathrm{GmbH}$ ). The polymerase chain reaction $(\mathrm{PCR})$ products were purified and labeled using the BigDye Terminator v3.1 Cycle Sequencing kit (Amoy Dx, Ltd., Xiamen, China), followed by sequencing in an ABI 3100 Genetic Analyzer (Applied Biosystems; Thermo Fisher Scientific, Inc., Waltham, MA, USA). All sequence variations were confirmed by multiple independent PCR amplifications and repeated sequencing reactions.

Immunohistochemical staining. Tissue sections $(5-\mu \mathrm{m}$ sections) obtained from the paraffin-embedded specimens were prepared on glass slides and then deparaffinized in xylene followed by a graded series of alcohol washes. The sections were placed in $0.1 \mathrm{~mol} / 1$ citrate buffer $(\mathrm{pH} 6.0)$, autoclaved at $121^{\circ} \mathrm{C}$ for $10 \mathrm{~min}$ and treated with $3 \% \mathrm{H}_{2} \mathrm{O}_{2}$ for $5 \mathrm{~min}$ to reduce endogenous peroxidase activity. The sections were then blocked with normal goat serum (Amoy Dx, Xiamen, China) for $15 \mathrm{~min}$ and then incubated with rabbit polyclonal antibodies targeting either ER- $\beta$ (catalog no., SC-6820; Santa Cruz Biotechnology, Inc., Santa Cruz, CA, USA) or p53 (catalog no., 2527s; Cell Signaling Technology, Inc., Beverly, MA, USA) at room temperature for $30 \mathrm{~min}$. The ER- $\beta$ and p53 antibodies were diluted 1:500 and 1:10, respectively, in phosphate-buffered saline. Biotinylated secondary anti-mouse antibodies (dilution, 1:100; catalog no., 7076s; Cell Signaling Technology, Inc.) were applied to the sections for $20 \mathrm{~min}$. Immunoperoxidase staining was subsequently performed using the EnVision kit (Dako Japan Co., Ltd., Kyoto, Japan) according to the manufacturer's protocol. Sections were observed using Olympus BX51 (Olympus, Tokyo, Japan).

Statistical analysis. All statistical analysis was performed using the SPSS 16.0 statistical software package (SPSS Inc., Chicago, IL, USA). All data are expressed as the mean \pm standard deviation. The $\chi^{2}$-test was used to investigate associations between EGFR mutations and clinical characteristics, including the expression of ER- $\beta$, age, gender, smoking history, histological type, histological differentiation, lymph node metastasis and distant metastasis. Multivariate analysis was performed using logistic regression. Survival curves were estimated using the Kaplan-Meier method. Progression-free survival (PFS) was defined as the time of diagnosis to the time of recurrence or the date of the final follow-up. Significant differences among subgroups were compared using the log-rank test. Cox proportional hazard regression analysis was used to examine the effects of EGFR mutations, expression of ER- $\beta$ and clinical variables on survival rates. Factors showing prognostic significance in the univariate analyses were entered as variables in the multivariate analysis. $\mathrm{P}<0.05$ was considered to indicate a statistically significant difference.

\section{Results}

EGFR mutation status in NSCLC tumors. Tumor specimens obtained from 83 patients with advanced NSCLC were analyzed for mutations in the EGFR gene. The tumors of $47(56.6 \%)$ patients were identified as EGFR wild-type (EGFR-wt) and those of $36(45.4 \%)$ patients were identified as EGFR mutant (EGFR-mut). It was found that $>95 \%$ of the patients with EGFR-mut tumors had adenocarcinomas, and $42.6 \%$ of the patients with EGFR-wt tumors had squamous carcinomas. The percentage of former and current smokers was significantly higher in the EGFR-wt group, compared with the EGFR-mut group (72.3, vs. 30.6\%, respectively), whereas the percentage of female patients was significantly higher in the EGFR-mut group, compared with the EGFR-wt group (61.1, vs. 17\%, respectively).

Expression of ER- $\beta$ and p53 in tumor specimens. Immunohistochemistry was performed to evaluate the expression of ER- $\beta$ and p53 in the tumors of the 83 patients with advanced 
Table I. Characteristics of the patients, according to EGFR status.

\begin{tabular}{|c|c|c|c|c|}
\hline Characteristic & $\begin{array}{l}\text { Number }(\%) \\
\quad(n=83)\end{array}$ & $\begin{array}{c}\text { EGFR wild-type } \\
\text { n }(\%)\end{array}$ & $\begin{array}{l}\text { EGFR mutant } \\
\mathrm{n}(\%)\end{array}$ & P-value \\
\hline Age (years) & & & & 0.580 \\
\hline$\leq 64$ & $46(55.4)$ & $26(31.3)$ & $20(24.1)$ & \\
\hline$>64$ & $37(45.6)$ & $21(25.3)$ & $16(19.3)$ & \\
\hline Gender & & & & $<0.001$ \\
\hline Female & $30(36.1)$ & $8(9.6)$ & $22(26.5)$ & \\
\hline Male & $53(63.9)$ & $39(47)$ & $14(16.9)$ & \\
\hline Differentiation & & & & 0.212 \\
\hline Well & $25(30.1)$ & $12(14.5)$ & $13(15.7)$ & \\
\hline Poor & $58(69.9)$ & $35(42.2)$ & $23(27.7)$ & \\
\hline Smoking status & & & & $<0.001$ \\
\hline Never smoked & $38(45.8)$ & $13(15.7)$ & $25(30.1)$ & \\
\hline Current and former smokers & $45(54.2)$ & $34(41)$ & $11(13.3)$ & \\
\hline Histology & & & & $<0.001$ \\
\hline Adenocarcinoma & $62(74.7)$ & $27(32.5)$ & $35(42.2)$ & \\
\hline Squamous & $21(25.3)$ & $20(24.1)$ & $1(1.2)$ & \\
\hline Lymph node metastasis & & & & 0.410 \\
\hline Yes & $53(63.9)$ & $31(37.3)$ & $22(26.5)$ & \\
\hline No & $30(36.1)$ & $16(19.3)$ & $14(16.9)$ & \\
\hline Distant metastasis & & & & 0.245 \\
\hline Yes & $46(55.4)$ & $24(28.9)$ & $22(26.5)$ & \\
\hline No & $37(45.6)$ & $23(27.7)$ & $14(16.9)$ & \\
\hline Expression of estrogen receptor- $\beta$ & & & & 0.006 \\
\hline Negative & $46(55.4)$ & $20(24.1)$ & $26(31.3)$ & \\
\hline Positive & $37(45.6)$ & $27(32.5)$ & $10(12)$ & \\
\hline Expression of p53 & & & & 0.381 \\
\hline Negative & $35(42.2)$ & $21(25.3)$ & $14(16.9)$ & \\
\hline Positive & $48(57.8)$ & $26(31.3)$ & $22(26.5)$ & \\
\hline
\end{tabular}

EGFR, epidermal growth factor receptor.

NSCLC. Representative examples of positive and negative ER- $\beta$ and p53 immunostaining are shown in Fig. 1. For each of these proteins, the patients were categorized into positive and negative expression groups depending upon whether or not protein staining was detectable in the tumor tissue samples. ER- $\beta$ and p53 were expressed in $37(45.6 \%)$ and $48(57.8 \%)$ of the 83 patient tumors, respectively. The percentage of samples with detectable expression of ER- $\beta$ was higher in the EGFR-wt patient group, compared with the EGFR-mut group (57.4, vs. $27.8 \%$, respectively). However, the percentage of samples positive for the expression of p53 was similar for the EGFR-wt and EGFR-mut patient groups (55.3, vs. 61.1\%, respectively). No significant correlation between the expression of p53 and EGFR mutations was found (Table I).

Association between EGFR mutations and clinicopathologic factors. In the univariate analysis, mutations in the EGFR gene were significantly associated with gender, smoking status, histology and the expression of ER- $\beta$ (Table I). No significant correlation was identified between EGFR mutations and well-differentiated tumors, lymph node metastasis and the expression of p53 (Table I). In the multivariate analysis, as shown in Table II, EGFR mutations were significantly associated with histology (OR 0.074; $\mathrm{P}=0.023)$ and the expression of ER- $\beta$ (OR 0.241; $\mathrm{P}=0.029)$. However, no significant correlations were observed between EGFR mutations and either gender (OR 3.649; $\mathrm{P}=0.105)$ or smoking status (OR 0.493; $\mathrm{P}=0.360$ ). The above findings indicated that there was a close correlation between the expression of ER- $\beta$ and the presence of EGFR mutations.

Affect of clinicopathologic factors, expression of ER- $\beta$ and EGFR mutations on PFS. Subsequently, survival analysis was performed on the 83 advanced NSCLC patients. The expression of ER- $\beta$ was associated with poor prognosis in terms of PFS. The median PFS was 8.5 months for the ER- $\beta$-postive expression group and 12.2 months for the ER- $\beta$-negative expression group $(\mathrm{P}=0.004$; Fig. $2 \mathrm{~A})$. However, within the 36 patient EGFR-mut group, the ER- $\beta$ expression status had no significant effect on PFS $(\mathrm{P}=0.085)$, as shown in Fig. $2 \mathrm{~B}$. 
Table II. Multivariate analysis of predictive factors for epidermal growth factor receptor mutations.

\begin{tabular}{lcc}
\hline Characteristic & OR (95\% CI) & P-value \\
\hline Age: $\leq 64$, vs. >64 years & $1.429(0.424-4.823)$ & 0.565 \\
Gender: Female, vs. male & $3.649(0.761-17.494)$ & 0.105 \\
Differentiation: Well, vs. poor & $3.061(0.773-12.126)$ & 0.111 \\
Smoking status: Never smoked, vs. current/former smoker & $0.493(0.108-2.245)$ & 0.360 \\
Histology: Squamous, vs. adenocarcinoma & $0.074(0.008-0.698)$ & 0.023 \\
Lymph node metastasis: Yes, vs. no & $0.790(0.209-2.986)$ & 0.729 \\
Distant metastasis: Yes, vs. no & $1.209(0.329-4.447)$ & 0.775 \\
Expression of estrogen receptor- $\beta$ : Negative, vs. positive & $0.241(0.067-0.865)$ & 0.029 \\
Expression of p53: Negative, vs. positive & $1.792(0.540-5.943)$ & 0.340
\end{tabular}

OR, odds ratio; CI, confidence interval.
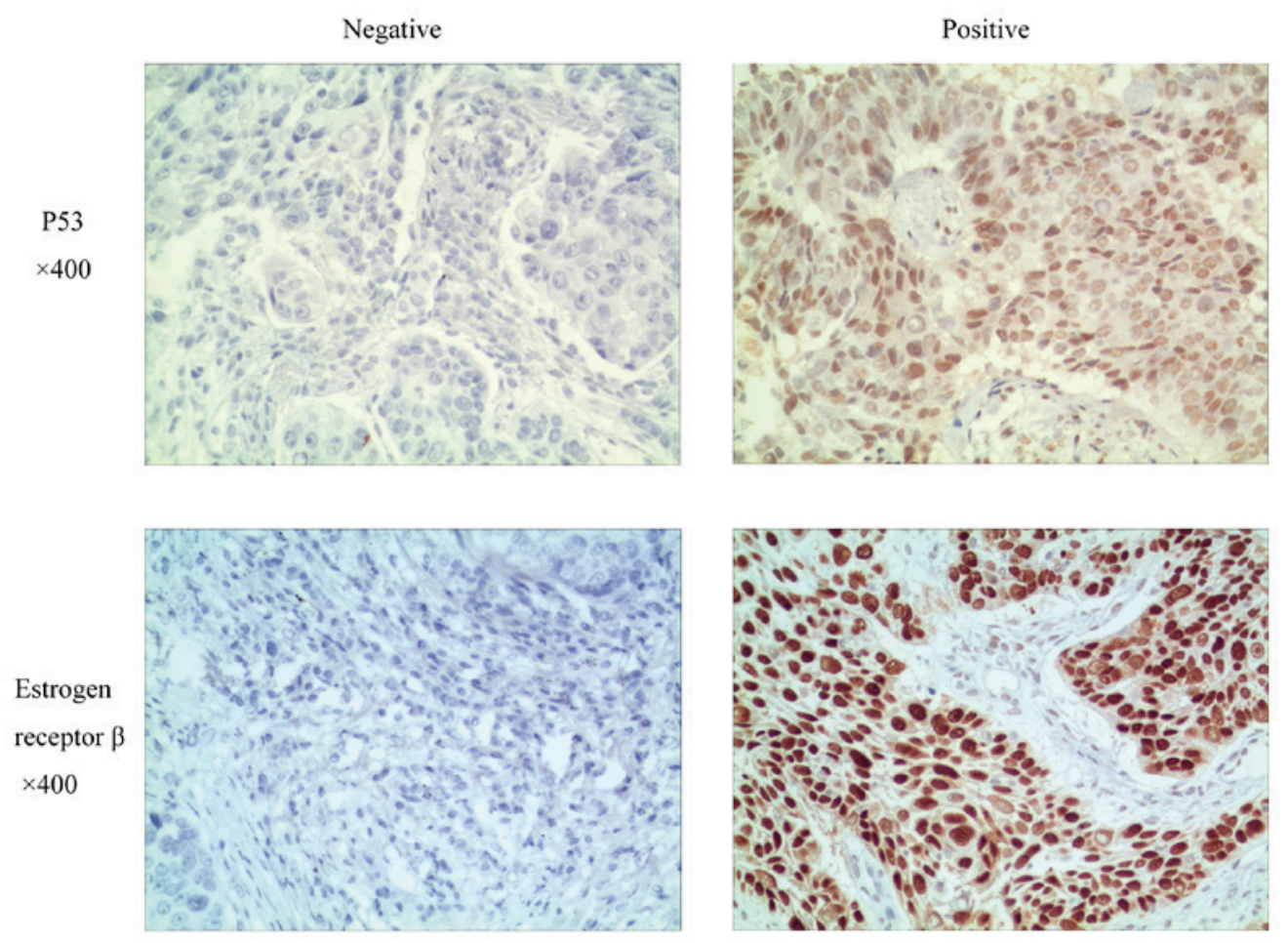

Figure 1. Representative examples of estrogen receptor- $\beta$ and p53 immunostaining in patient-derived tumor tissue sections. Examples of staining patterns scored as negative (left) and positive (right) for protein expression are shown for each protein.

EGFR mutations were associated with favorable prognosis in terms of PFS. The median PFS was 14.6 months in the EGFR-mut group, compared with 7.6 months in the EGFR-wt group ( $\mathrm{P}<0.001$; Fig. $2 \mathrm{C}$ ). In addition, no significant correlation was observed between the expression of p53 and PFS $(\mathrm{P}=0.659$; Fig. 2D). These data indicated that EGFR mutations and the expression of ER- $\beta$ were significant determinants of prognosis in patients with advanced NSCLC.

The results of the Cox regression analysis of clinical variables associated with PFS for the 83 patients are summarized in Table III. In the univariate analysis, survival rates were significantly associated with conventional prognostic factors, including smoking status $(\mathrm{P}=0.004)$, histology $(\mathrm{P}=0.004)$, lymph node metastasis $(\mathrm{P}=0.001)$, EGFR mutations $(\mathrm{P}<0.001)$ and expression of ER- $\beta(\mathrm{P}=0.007)$. The multivariate analysis revealed that EGFR mutations $(\mathrm{P}<0.001)$ and lymph node metastasis $(\mathrm{P}=0.003)$ were significant prognostic factors. However, no differences in PFS were observed with respect to histological type and the ER- $\beta$ expression status.

\section{Discussion}

In the present study, a cohort of 83 patients with advanced NSCLC was analyzed. The results provided evidence for an association between the expression of ER- $\beta$ and the presence of EGFR mutations, and demonstrated the prognostic significance of this association. The results showed that there was a significant correlation between EGFR mutations 
Table III. Results of the univariate and multivariate analyses of selected factors for PFS in all patients.

\begin{tabular}{|c|c|c|c|c|}
\hline \multirow[b]{2}{*}{ Variable } & \multicolumn{2}{|c|}{ Univariate } & \multicolumn{2}{|c|}{ Multivariate } \\
\hline & $\mathrm{HR}(95 \% \mathrm{CI})$ & P-value & HR $(95 \% \mathrm{CI})$ & P-value \\
\hline Gender (male, vs. female) & $0.624(0.383-1.017)$ & 0.059 & & \\
\hline Age $(\leq 64$, vs. $>64$ years $)$ & $0.929(0.593-1.456)$ & 0.749 & & \\
\hline Smoking status (never, vs. current/former) & $2.012(1.254-3.229)$ & 0.004 & $1.172(0.682-2.012)$ & 0.566 \\
\hline Histology (adenocarcinoma, vs. squamous) & $2.168(1.273-3.695)$ & 0.004 & $1.111(0.670-1.844)$ & 0.747 \\
\hline Histological differentiation (well, vs. poor) & $0.873(0.535-1.424)$ & 0.586 & & \\
\hline Lymph node metastasis (yes, vs. no) & $2.576(1.493-4.443)$ & 0.001 & $2.400(1.353-4.257)$ & 0.003 \\
\hline Distant metastasis (yes, vs. no) & $1.294(0.824-2.032)$ & 0.264 & & \\
\hline EGFR (mutated, vs. wild type) & $0.238(0.139-0.409)$ & $<0.001$ & $0.284(0.150-0.537)$ & $<0.001$ \\
\hline Estrogen receptor- $\beta$ (positive, vs. negative) & $1.924(1.197-3.092)$ & 0.007 & $1.111(0.670-1.844)$ & 0.684 \\
\hline P53 (positive, vs. negative) & $1.102(0.698-1.738)$ & 0.678 & & \\
\hline
\end{tabular}

EGFR, epidermal growth factor receptor; HR, hazard ratio; CI, confidence interval.

A

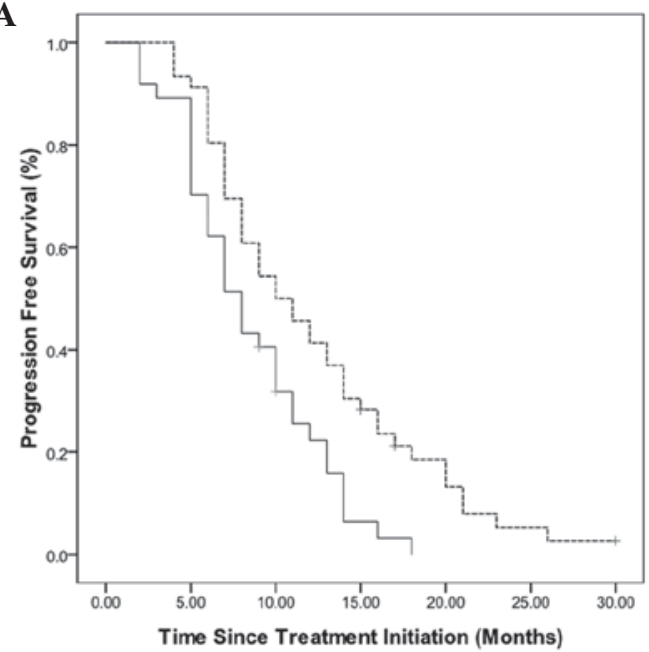

C

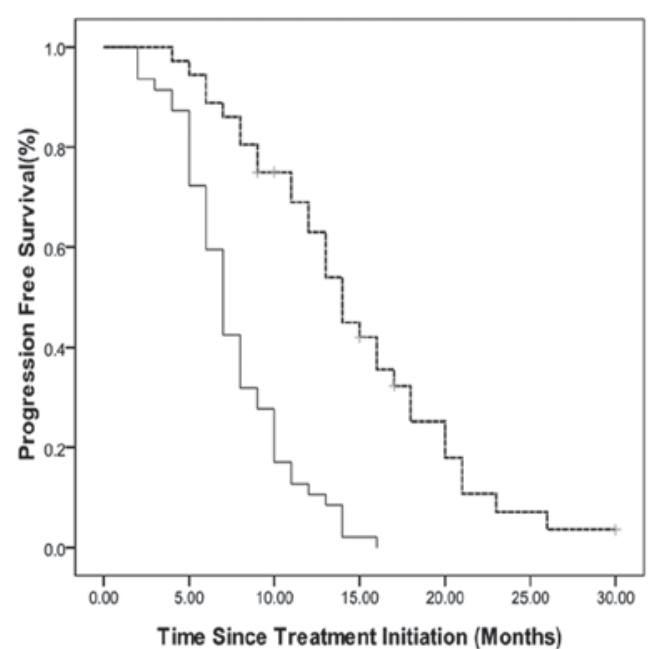

B

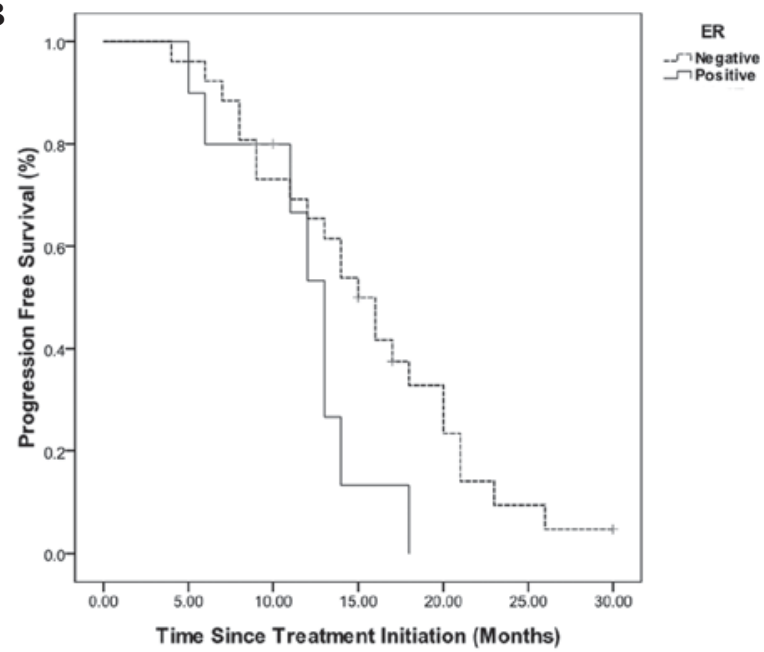

D

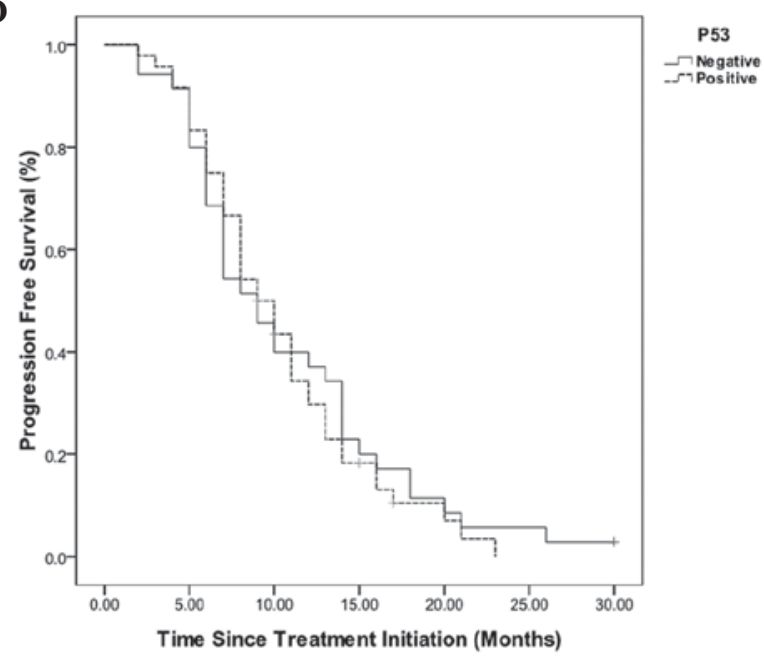

Figure 2. Kaplan-Meier PFS curves. (A) PFS curves for the 83 patients, stratified according to ER- $\beta$ expression status. The median survival rate for ER- $\beta$-negative patients was 12.2 months, compared with 8.5 months for ER- $\beta$-positive patients $(\mathrm{P}=0.004)$. (B) PFS curves for the EGFR-mut subgroup of 36 patients, stratified according to ER- $\beta$ expression status. The median survival rate for the ER- $\beta$-negative patients was 15.4 months, compared with 11.9 months for the ER- $\beta$-positive patients ( $\mathrm{P}=0.085)$. (C) PFS curves for the 83 patients, stratified according to EGFR mutation status. The median survival rate of the EGFR-wt patients was 7.6 months, compared with 14.6 months for the EGFR-mut patients $(\mathrm{P}<0.001)$. (D) PFS curves for the 83 patients, stratified according to p53 expression status. The median survival rate for p53-negative patients was 10.8 months, compared with 10.4 months for p53-positive patients $(\mathrm{P}=0.659)$. $\mathrm{PFS}$, progression-free survival; ER- $\beta$, estrogen receptor- $\beta$; EGFR, epidermal growth factor receptor; wt, wild-type; mut, mutant. 
and clinicopathologic factors, including histology and the expression of ER- $\beta$. There was a significant trend toward improved PFS for patients with EGFR mutations, compared with those without mutations. It was also found that patients with ER- $\beta$ tumors had a significantly poorer prognosis. These findings indicated that EGFR mutations and the expression of ER- $\beta$ may represent clinically useful prognostic markers in advanced NSCLC.

In NSCLC cells, estrogen biosynthesis is driven by intrinsically expressed aromatase (30), resulting in the activation of ER signaling, and the promotion of tumor development and progression $(2,7,31)$. Although the detection of ER- $\alpha$ and/or the expression of ER- $\beta$ by immunohistochemical techniques has been associated with clinical outcome in certain studies $(11,13,26)$, findings regarding the frequency of expression of these receptors in NSCLC are inconsistent $(11,13,27,32)$. These differences may be a consequence of inter-study variations in factors, including patient cohort characteristics (13), the antibodies used and their associated dilutions. These discrepancies may obscure the significance of hormone receptor expression status on patient clinicopathologic characteristics and prognosis. In the present study, ER- $\beta$ was found to be expressed in the tumors of 37 (45.6\%) patients, and was more frequently associated with wild-type EGFR status. A significant negative correlation was identified between the expression of ER- $\beta$ and EGFR mutations, which was consistent with previous reports $(11,12,25,27)$. The present study also found that the expression of ER- $\beta$ was significantly associated with shorter PFS in the 83 patients examined. However, no significant correlation between the expression of ER- $\beta$ and PFS was found for the 36 EGFR-mut patients. These differences may be a consequence of the low number of patients with EGFR mutations in the present study. Although not significant, the PFS for the 36 EGFR-mut patients who were also negative for the expression of ER- $\beta$ was longer, compared with that for the patients positively expressing ER- $\beta$ (15.4, vs. 11.9 months, respectively). The above results indicated that female hormone-associated factors, including aromatase and the expression of ER- $\beta$, affect the outcomes for patients with NSCLC associated with EGFR mutations, suggesting that the ER and EGFR pathways contribute to the progression of NSCLC.

EGFR mutations are considered to be an early event in the pathogenesis of NSCLC, and are more commonly observed in women, non-smokers and in patients with adenocarcinoma $(23,24,33)$. It is now universally accepted that the presence or absence of EGFR mutations can be used to define two types of NSCLC with differing biology, therapeutic options and outcomes (34). In the present study, 97.2\% of EGFR-mut tumors were adenocarcinomas, and the EGFR mutation frequency was higher in non-smokers and female patients. These results are all consistent with those of previous reports $(23,24)$. In addition, the present study found that patients with EGFR mutations had a significantly more favorable prognosis, compared with those without EGFR mutations. These data indicated that EGFR mutations wer the most important factor in determining the prognosis of patients with advanced NSCLC. The present study also evaluated the effect of gender, smoking history and the ER- $\beta$ expression status on PFS in the 36 EGFR-mut patients; however, no significant differences were found (data not shown). This may have been due to the low number of EGFR-mut patients in the present study. Therefore, a clinical investigation involving a larger number of patients with EGFR mutations is required to further clarify the correlation between clinicopathologic factors and prognosis within this specific advanced NSCLC patient subgroup.

The 553 tumor suppressor protein regulates multiple important cellular processes, including cell-cycle arrest, senescence and apoptosis, and alterations in its activity are involved in tumorigenesis. Therefore, the loss of p53 function may lead to unchecked cellular proliferation, tumor growth and therapeutic resistance $(35,36)$. The present study also investigated the effect of the expression of $\mathrm{p} 53$ in patients with advanced NSCLC. No correlation was found between the expression of p53 and the presence of EGFR mutations (Tables I and II). In addition, no significant correlation was observed between the expression of p53 and PFS. A previous study reported that non-disruptive mutations in the TP53 gene are an independent prognostic factor of shorter survival rates in advanced NSCLC (37), whereas another study showed that p53 mutations are significantly correlated with tumor relapse in patients with stage I disease (38). The tumor suppressor gene, TP53, is the most frequently mutated gene in NSCLC (39). Several of these mutations result in a stable protein, with significant loss of activity. However, the present study did not investigate the significance of p53 mutations. Clinical trials are warranted to determine the frequency, nature and prognostic significance of p53 mutations in patients with advanced NSCLC.

In conclusion, the present study demonstrated a significant correlation between the expression of ER- $\beta$ and the presence of EGFR mutations in advanced NSCLC. EGFR mutations had a negative association with the expression of ER- $\beta$. The expression of ER- $\beta$ was associated with poor prognosis, whereas EGFR mutations were associated with a more favorable patient outcome. These findings suggested that the expression of ER- $\beta$ and presence of EGFR mutations may be used as surrogate markers for the prognosis of patients with advanced NSCLC.

\section{Acknowledgements}

This study was supported by the National Natural Science Foundation of China (grant no. 81172172). The authors would like to thank Mr. Guo Zhen-Li (Department of Respiratory Oncology, Anhui Provincial Cancer Hospital, Hefei, China) for tissue sample collection and Mr. Wang Xu (School of Public Health, Anhui Medical University, Hefei, China) for statistical analysis.

\section{References}

1. Jemal A, Bray F, Center MM, Ferlay J, Ward E and Forman D: Global cancer statistics. CA Cancer J Clin 61: 69-90, 2011.

2. Pietras RJ, Márquez DC, Chen HW, Tsai E, Weinberg O and Fishbein M: Estrogen and growth factor receptor interactions in human breast and non-small cell lung cancer cells. Steroids 70: 372-381, 2005

3. Sun S, Schiller JH and Gazdar AF: Lung cancer in never smokers-a different disease. Nat Rev Cancer 7: 778-790, 2007.

4. Yano T, Haro A, Shikada Y, Maruyama R and Maehara Y: Non-small cell lung cancer in never smokers as a representative 'non-smoking-associated lung cancer': Epidemiology and clinical features. Int J Clin Oncol 16: 287-293, 2011. 
5. Radzikowska E, Głaz P and Roszkowski K: Lung cancer in women: Age, smoking, histology, performance status, stage, initial treatment and survival. Population-based study of 20 561 cases. Ann Oncol 13: 1087-1093, 2002.

6. Yano T, Miura N, Takenaka T, Haro A, Okazaki H, Ohba T, Kouso H, Kometani T, Shoji F and Maehara Y: Never-smoking nonsmall cell lung cancer as a separate entity: Clinicopathologic features and survival. Cancer 113: 1012-1018, 2008.

7. Stabile LP, Lyker JS, Gubish CT, Zhang W, Grandis JR and Siegfried JM: Combined targeting of the estrogen receptor and the epidermal growth factor receptor in non-small cell lung cancer shows enhanced antiproliferative effects. Cancer Res 65: 1459-1470, 2005.

8. Stabile LP, Davis AL, Gubish CT, Hopkins TM, Luketich JD, Christie N, Finkelstein S and Siegfried J: Human non-small cell lung tumors and cells derived from normal lung express both estrogen receptor alpha and beta and show biological responses to estrogen. Cancer Res 62: 2141-2150, 2002.

9. Weinberg OK, Marquez-Garban DC, Fishbein MC, Goodglick L, Garban HJ, Dubinett SM and Pietras RJ: Aromatase inhibitors in human lung cancer therapy. Cancer Res 65: 11287-11291, 2005.

10. Mah V, Seligson DB, Li A, Márquez DC, Wistuba II, Elshimali Y, Fishbein MC, Chia D, Pietras RJ and Goodglick L: Aromatase expression predicts survival in women with early-stage non-small cell lung cancer. Cancer Res 67: 10484-10490, 2007.

11. Raso MG, Behrens C, Herynk MH, Liu S, Prudkin L, Ozburn NC, Woods DM, Tang X, Mehran RJ, Moran C, et al: Immunohistochemical expression of estrogen and progesterone receptors identifies a subset of NSCLCs and correlates with EGFR mutation. Clin Cancer Res 15: 5359-5368, 2009.

12. Nose N, Sugio K, Oyama T, Nozoe T, Uramoto H, Iwata T, Onitsuka T and Yasumoto K: Association between estrogen receptor-beta expression and epidermal growth factor receptor mutation in the postoperative prognosis of adenocarcinoma of the lung. J Clin Oncol 27: 411-417, 2009.

13. Stabile LP, Dacic S, Land SR, Lenzner DE, Dhir R, Acquafondata M, Landreneau RJ, Grandis JR and Siegfried JM: Combined analysis of estrogen receptor beta- 1 and progesterone receptor expression identifies lung cancer patients with poor outcome. Clin Cancer Res 17: 154-164, 2011

14. Siegfried JM, Hershberger PA and Stabile LP: Estrogen receptor signaling in lung cancer. Semin Oncol 36: 524-531, 2009.

15. Márquez-Garbán DC, Chen HW, Fishbein MC, Goodglick L and Pietras RJ: Estrogen receptor signaling pathways in human non-small cell lung cancer. Steroids 72: 135-143, 2007.

16. Liu Y, Inoue M, Sobue T and Tsugane S: Reproductive factors, hormone use and the risk of lung cancer among middle-aged never-smoking Japanese women: A large-scale population-based cohort study. Int J Cancer 117: 662-666, 2005.

17. Hershberger PA, Vasquez AC, Kanterewicz B, Land S Siegfried JM and Nichols M: Regulation of endogenous gene expression in human non-small cell lung cancer cells by estrogen receptor ligands. Cancer Res 65: 1598-1605, 2005.

18. Mollerup S, Jørgensen K, Berge G and Haugen A: Expression of estrogen receptors alpha and beta in human lung tissue and cell lines. Lung cancer 37: 153-159, 2002.

19. Kawai H, Ishii A, Washiya K, Konno T, Kon H, Yamaya C, Ono I, Minamiya Y and Ogawa J: Estrogen receptor alpha and beta are prognostic factors in non-small cell lung cancer. Clin Cancer Res 11: 5084-5089, 2005

20. Alì G, Donati V, Loggini B, Servadio A, Dell'Omodarme M, Prati MC, Camacci T, Lucchi M, Melfi F, Mussi A and Fontanini G: Different estrogen receptor beta expression in distinct histologic subtypes of lung adenocarcinoma. Hum Pathol 39: 1465-1473, 2008

21. Toh CK, Ahmad B, Soong R, Chuah KL, Tan SH, Hee SW, Leong SS, Tan EH and Lim WT: Correlation between epiderma growth factor receptor mutations and expression of female hormone receptors in East-Asian lung adenocarcinomas. J Thorac Oncol 5: 17-22, 2010

22. Pietras RJ and Márquez-Garbán DC: Membrane-associated estrogen receptor signaling pathways in human cancers. Clin Cancer Res 13: 4672-4676, 2007.

23. Shigematsu H, Lin L, Takahashi T, Nomura M, Suzuki M, Wistuba II, Fong KM, Lee H, Toyooka S, Shimizu N, et al: Clinical and biological features associated with epidermal growth factor receptor gene mutations in lung cancers. J Nat Cancer Inst 97: 339-346, 2005.
24. Kosaka T, Yatabe Y, Endoh H, Kuwano H, Takahashi T and Mitsudomi T: Mutations of the epidermal growth factor receptor gene in lung cancer: Biological and clinical implications. Cancer Res 64: 8919-8923, 2004

25. Garon EB, Pietras RJ, Finn RS, Kamranpour N, Pitts S, Márquez-Garbán DC, Desai AJ, Dering J, Hosmer W, von Euw EM, et al: Antiestrogen fulvestrant enhances the antiproliferative effects of epidermal growth factor receptor inhibitors in human non-small cell lung cancer. J Thorac Oncol 8: 270-278, 2013.

26. Nose $\mathrm{N}$, Uramoto $\mathrm{H}$, Iwata $\mathrm{T}$, Hanagiri $\mathrm{T}$ and Yasumoto $\mathrm{K}$ : Expression of estrogen receptor beta predicts a clinical response and longer progression-free survival after treatment with EGFR-TKI for adenocarcinoma of the lung. Lung Cancer 71: 350-355, 2011.

27. Sun HB, Zheng Y, Ou W, Fang Q, Li P, Ye X, Zhang BB, Yang H and Wang SY: Association between hormone receptor expression and epidermal growth factor receptor mutation in patient operated on for non-small cell lung cancer. Ann Thorac Surg 91: 1562-1567, 2011

28. Mountain CF: Revisions in the International System for Staging Lung Cancer. Chest 111: 1710-1717, 1997.

29. Zhou Q, Zhang XC, Chen ZH, Yin XL, Yang JJ, Xu CR, Yan HH, Chen HJ, Su J, Zhong WZ, et al: Relative abundance of EGFR mutations predicts benefit from gefitinib treatment for advanced non-small-cell lung cancer. J Clin Oncol 29: 3316-3321, 2011.

30. Niikawa H, Suzuki T, Miki Y, Suzuki S, Nagasaki S, Akahira J, Honma S, Evans DB, Hayashi S, Kondo T and Sasano H: Intratumoral estrogens and estrogen receptors in human non-small cell lung carcinoma. Clin Cancer Res 14: 4417-4426, 2008.

31. Hershberger PA, Stabile LP, Kanterewicz B, Rothstein ME, Gubish CT, Land S, Shuai Y, Siegfried JM and Nichols M: Estrogen receptor beta (ERbeta) subtype-specific ligands increase transcription, $\mathrm{p} 44 / \mathrm{p} 42$ mitogen activated protein kinase (MAPK) activation and growth in human non-small cell lung cancer cells. J Steroid Biochem Mol Biol 116: 102-109, 2009.

32. Miki Y, Abe K, Suzuki S, Suzuki T and Sasano H: Suppression of estrogen actions in human lung cancer. Mol Cell Endocrinol 340: 168-174, 2011.

33. Ji H, Li D, Chen L, Shimamura T, Kobayashi S, McNamara K, Mahmood U, Mitchell A, Sun Y, Al-Hashem R, et al: The impact of human EGFR kinase domain mutations on lung tumorigenesis and in vivo sensitivity to EGFR-targeted therapies. Cancer Cell 9: 485-495, 2006.

34. Rosell R, Moran T, Queralt C, Porta R, Cardenal F, Camps C, Majem M, Lopez-Vivanco G, Isla D, Provencio M, et al: Screening for epidermal growth factor receptor mutations in lung cancer. N Engl J Med 361: 958-967, 2009.

35. Levine AJ and Oren M: The first 30 years of p53: Growing ever more complex. Nat Rev Cancer 9: 749-758, 2009.

36. Brown CJ, Lain S, Verma CS, Fersht AR and Lane DP: Awakening guardian angels: Drugging the p53 pathway. Nat Rev Cancer 9: 862-873, 2009.

37. Molina-Vila MA, Bertran-Alamillo J, Gascó A, Mayo-de-las-Casas C, Sánchez-Ronco M, Pujantell-Pastor L, Bonanno L, Favaretto AG, Cardona AF, Vergnenègre A, et al: Nondisruptive p53 mutations are associated with shorter survival in patients with advanced non-small cell lung cancer. Clin Cancer Res 20: 4647-4659, 2014.

38. Lin MW, Wu CT, Shih JY, Chang YL and Yang PC: Clinicopathologic characteristics and prognostic significance of EGFR and p53 mutations in surgically resected lung adenocarcinomas $\leq 2 \mathrm{~cm}$ in maximal dimension. J Surg Oncol 110: 99-106, 2014.

39. Forbes SA, Bindal N, Bamford S, Cole C, Kok CY, Beare D, Jia M, Shepherd R, Leung K, Menzies A, et al: COSMIC: Mining complete cancer genomes in the catalogue of somatic mutations in cancer. Nucleic Acids Res 39 (Database issue): D945-D950, 2011. 